\title{
MODELS DE TRADUCCIÓ LITERÀRIA I AUDIOVISUAL EN CATALÀ COL·LOQUIAL: EL CAS DE JACKIE BROWN DE QUENTIN TARANTINO
}

\author{
MODELS OF LITERARY AND AUDIO-VISUAL \\ TRANSLATION IN COLLOQUIAL CATALAN: THE CASE OF \\ QUENTIN TARANTINO'S JACKIE BROWN
}

\author{
Dídac Pujol \\ Universitat Pompeu Fabra \\ didac.pujol@upf.edu
}

Resum: Aquest article tracta dels models de traducció col-loquial cap al català en el cas de la versió doblada (1997), la versió subtitulada (1997) i el guió traduït (1998) de Jackie Brown (1997) de Quentin Tarantino. El nucli de l'article és l'anàlisi i la comparació de la fonètica, la morfologia, la sintaxi i el lèxic de cada traducció catalana, que s'emmarca en els models lingüístics i de traducció vigents en el període objecte d'estudi. La conclusió a la qual s'arriba és que les tres traduccions utilitzen models de llengua col-loquial diferents. El guió traduït basteix un model trencador, sobretot en qüestions de representació fonètica i en el lèxic castellà que utilitza. La versió doblada s'adequa als criteris de traducció i doblatge de $T V_{3}$ : d'una banda, presenta una sintaxi relativament col-loquial (menys col-loquial que la de la versió subtitulada, però no tant com la del guió traduiit); i, d'altra banda, fa ús d'una morfologia estàndard que explota poc els recursos col-loquials de la llengua meta. La versió subtitulada s'acosta més a la parla col.loquial que la versió doblada, sobretot en qüestions de lèxic, àmbit en el qual utilitza molts menys castellanismes que el guió traduït.

Paraules clau: traducció literària, traducció audiovisual, doblatge, subtitulació, català col-loquial, models de traducció col-loquial, Quentin Tarantino, Jackie Brown.

Abstract: This article deals with the models of colloquial translation into Catalan in the case of the dubbed version (1997), the subtitled version (1997) and the translated script (1998) of Quentin Tarantino's Jackie Brown (1997). At the core of the article lies the analysis and the comparison of the phonetics, the morphology, the syntax and the lexicon of each Catalan translation, which is contextualized within the linguistic and translation models current at the time. The conclusion is that the three translations make use of different colloquial language models. The translated 
Dídac Pujol

Models de traducció literària i audiovisual en català col-loquial

script constitutes a disruptive model, especially regarding phonetic representation and the Spanish lexicon deployed. The dubbed version follows TV3's translation and dubbing criteria: on the one hand, its syntax is relatively colloquial (less colloquial than that of the subtitled version, but not so much as the translated script); on the other hand, its morphology is standard and underexploits the colloquial resources of the target language. The subtitled version is more colloquial than the dubbed one, especially as far as the lexicon is concerned, using far fewer Hispanicisms than the translated script.

Key words: literary translation, audio-visual translation, dubbing, subtitling, colloquial Catalan, colloquial translation models, Quentin Tarantino, Jackie Brown. 


\section{DÍDAC PUJOL}

\section{MODELS DE TRADUCCIÓ LITERÀRIA I AUDIOVISUAL

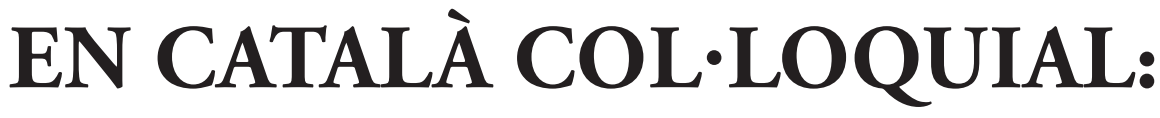 EL CAS DE JACKIE BROWN DE QUENTIN TARANTINO}

\section{INTRODUCCIÓ}

L'objectiu d'aquest article és estudiar els models de traducció del català col-loquial en el seu vessant literari i audiovisual. Per fer-ho, s'analitzaran i es compararan tres traduccions catalanes (el doblatge, la subtitulació i el guió escrit) de Jackie Brown, una obra del cineasta contemporani Quentin Tarantino. No se n'oferirà una llista exhaustiva amb tots els fenòmens col-loquials, ni es donaran dades quantitatives percentuals, però les diferents anàlisis i exemples que presentarem són representatius (qualitativament i quantitativament) dels fenòmens col-loquials que hi ha en cadascuna de les traduccions. Com veurem al llarg de l'article, les tres traduccions s'emmarquen en un model de llengua colloquial diferent.

Atès que aquest no és un article pròpiament sobre traducció, sinó sobre models de llengua en traducció, no ens centrarem en la comparació de l'original anglès amb les traduccions catalanes, sinó que prendrem com a punt de partida l'anàlisi de les traduccions en si mateixes, i citarem l'original anglès només en comptades ocasions, quan sigui estrictament necessari. Sigui com sigui, cal deixar clar que Jackie Brown és una pel-lícula on abunda el llenguatge col-loquial, i d'aquí que les traduccions utilitzin, en major o menor grau, un llenguatge també col.loquial. 
Dídac Pujol

Models de traducció literària i audiovisual en català col-loquial

Després de Reservoir Dogs (1992) i de Pulp Fiction (1994), el cineasta nord-americà Quentin Tarantino (nascut el 1963) va dirigir Jackie Brown (1997). ${ }^{1}$ La pel.lícula es va estrenar a EUA el 25 de desembre de 1997. Jackie Brown es va doblar i subtitular al català i al castellà als estudis de doblatge Soundtrack, de Barcelona, el mateix any de la seva estrena a EUA, el 1997. Al cap de poc, el 23 de febrer de 1998, la pel.lícula es va estrenar a les cartelleres catalanes i espanyoles. Jackie Brown va ser emesa per TVC (Televisió de Catalunya) per primer cop el I4 de setembre de 2000, i va aparèixer en DVD el 2002: aquest DVD conté la versió original anglesa i doblada al català i al castellà, a més dels subtítols en anglès, català i castellà. La traducció i l'ajustament per al doblatge al català són, segons consta a la fitxa de la pel-lícula, d'Albert Pejó (<http:// www.eldoblatge.com/fitxa_doblatge/22>). ${ }^{2}$ Pel que fa a la subtitulació de la pel.lícula en català i en castellà, ni el subtitulador ni l'estudi de subtitulació no figuren enlloc: ni a les bases de dades de doblatge (<http://www.eldoblatge.com, http://www.eldoblaje. com>), ni a la fitxa tècnica del DVD de la pel-lícula (Tarantino 2002).

A més de sortir com a pel-lícula, de Jackie Brown també se'n va publicar el guió original anglès (Nova York, Miramax Books): la data és la mateixa que la de l'estrena de la pel.lícula a EUA, és a dir, el 25 de desembre de 1997. Aprofitant l'èxit de taquilla de les pel-lícules anteriors de Tarantino, sobretot de Pulp Fiction, també es va publicar el guió en català: si la pel-lícula s'estrenava a les cartelleres catalanes el 23 de febrer de 1998, el guió català va veure la llum de la mà d'Editorial Empúries quatre dies més tard, el 27 de febrer de 1998 (segons consta a la pàgina de crèdits de Tarantino 1998b). La traducció era de Laura Escorihuela. ${ }^{3}$

El nostre corpus, doncs, està constituït per una pel-lícula i un guió original en anglès i, sobretot, per tres traduccions al català: la del doblatge, la de la subtitulació $i$ la del guió. Els casos analitzats no s'han triat a l'atzar, ni tampoc a partir d'un subcorpus (per exemple, diversos fragments). Dit d'una altra manera: tant els originals en anglès com les traduccions catalanes han estat buidades exhaustivament $\mathrm{i}$, a l'hora de dur a terme aquest estudi, s'han agrupat per categories els fenòmens més recurrents $\mathrm{i}$ significatius de tot el corpus. Val la pena remarcar que la distància temporal entre els

I. Abans havia codirigit Four Rooms (I995).

2. Val a dir que de la traducció al castellà se’n va encarregar una altra persona, Darryl Clerk, i que l'ajustador al castellà és Manuel García Guevara (<http://www.eldoblaje.com/datos/FichaPelicula.asp?id=242>).

3. El guió castellà, traduït per Ana Bustelo, el va publicar a Barcelona l'editorial Grijalbo Mondadori poc després: va aparèixer al març de I998, segons consta a la base de dades de l'ISBN espanyol. 
originals (guió i pel-lícula) i les traduccions és irrisòria: totes són obres coetànies que abracen un període de publicació que va des de finals de 1997 fins a principis de 1998.

\section{LES DIFERÈNCIES ENTRE LES TRADUCCIONS}

$\mathrm{Si}$, a banda de les traduccions que tenim, disposéssim de traduccions (doblatge, subtítols i guió) més recents de Jackie Brown, seria interessant determinar fins a quin punt el factor diacrònic és important a l'hora de traduir el llenguatge col.loquial. ${ }^{4}$ El fet, però, és que en el nostre corpus la distància cronològica entre els originals i les diverses traduccions de què disposem és ínfima: a tot estirar, és d'uns quants mesos (o fins i tot setmanes), de manera que el factor temps no explica que ens trobem davant de traduccions força diferents. Sí que ho fan, però, tres altres factors: (I) l'autoria de les traduccions; (2) el gènere dels originals i de les traduccions; i (3) els models de llengua col-loquial que han fet servir els traductors.

Pel que fa a l'autoria de les traduccions, el corpus analitzat deixa ben clar que és diferent en tots tres casos: la traducció per al doblatge i la posterior adaptació (també anomenada «ajust») són d'Albert Pejó, la traducció del guió escrit és de Laura Escorihuela, i la traducció per a la subtitulació és anònima, però certament no pas d'Albert Pejó (ni de Laura Escorihuela), atès que les divergències lingüístiques entre la versió doblada i la subtitulada (i el guió traduït) són prou acusades perquè es pugui afirmar que són obra d'autors diferents.

El text doblat pertany al mode oral, mentre que els subtítols i el guió pertanyen al mode escrit. El gènere al qual pertanyen el text doblat i els subtítols és la "traducció audiovisual», puix que s'integren en la pel.lícula, que té un format audiovisual. A diferència dels subtítols, però, el guió traduït no està pensat per ser llegit en un format audiovisual, sinó en un format de llibre, i com a tal l'encabirem dins el gènere "traducció literària», de la mateixa manera que hi inclouríem la traducció d'un guió teatral o d'un còmic. ${ }^{5}$ En aquest sentit, és revelador el text de la «Nota editorial» que apareix (només) en el guió català: "Jackie Brown és un guió pensat per ser llegit al

4. Per a una visió de conjunt sobre la importància del factor diacrònic en els models de traducció literària en català al llarg del segle xx, vegeu Marco (2000).

5. Tant el guió anglès com el castellà contenen diverses imatges (fotogrames) de la pel-lícula al llarg del llibre. El guió català, però, no inclou cap imatge de la pel-lícula, excepte a la coberta davantera. 
Dídac Pujol

Models de traducció literària i audiovisual en català col-loquial

marge de la pel-lícula: tant les acotacions com els diàlegs tenen entitat literària pròpia, i així han estat concebuts» (Tarantino 1998b: 5). Aquí cal entendre el terme «literari» com a adjectiu que s'aplica a un text que, per mitjà de l'escriptura, té (i és concebut $\mathrm{amb})$ un fi estètic.

Continuant amb el gènere, sembla clar que, de la mateixa manera que el traductor condiciona el producte final, el gènere del qual ( $\mathrm{i}$ al qual) es tradueix també ho fa. Així, doncs, fins i tot si el traductor fos el mateix en tots tres casos (doblatge, subtitulació, guió), els resultats obtinguts serien relativament diferents, per dos motius, tots ells relacionats amb el gènere. En primer lloc, perquè el text del guió original difereix del text de la pel-lícula que diuen els actors: tot i que la pel-lícula segueix de prop el guió escrit en què es basa, a la pel-lícula hi ha canvis d'escenari, a més d'afegitons, supressions i modificacions en el diàleg que devien sorgir durant el rodatge i la posterior edició del material rodat. ${ }^{6}$ En segon lloc, cal tenir en compte que el doblatge i la subtitulació tenen uns condicionants que no té la traducció d'un guió. Els principals constrenyiments del doblatge ocorren durant la fase posterior a la traducció, és a dir, durant l'ajust o adaptació: són la sincronia fonètica o labial, la sincronia cinètica i la isocronia (Chaume 2003: I28-I3I). Els principals constrenyiments de la subtitulació, en canvi, són la llargada limitada dels subtítols (el text subtitulat sol ser més sintètic que el doblat), la velocitat amb què apareixen els subtítols i la velocitat amb què parlen els actors (Chaume 2003: I64-I7I), les quals coses obliguen el subtitulador a usar estratègies com l'omissió i la condensació (Bartoll 20I2: 150-I57). Aquestes restriccions (o característiques pròpies del doblatge i de la subtitulació) no afecten la traducció del guió escrit, en què el traductor s'ha d'ajustar, com a molt, al llibre d'estil de l'editorial, si és que existeix.

Arribats aquí, i abans d'emprendre l'anàlisi i la comparació de les traduccions, ens podem preguntar fins a quin punt és vàlid, metodològicament, comparar tres traduccions que no pertanyen al mateix gènere i que, per tant, serien diferents fins $i$ tot en el cas que el traductor fos el mateix. Comparar un doblatge amb una subtitulació i amb un guió no és, en el fons, com comparar pomes i peres (o pomes, peres i taronges)? Sí i no. Sí, perquè, evidentment, el material objecte d'anàlisi pertany a tres

6. A diferència del guió anglès i del castellà, el guió català marca amb una ratlla vertical els fragments de diàleg suprimits a la pel-lícula. Soler Pardo (2013: I29-130) observa que, pel que fa al renec fuck (incloent els compostos i derivats), la freqüència d'ús és més alta a la pel-lícula que en el guió publicat, segurament perquè una presència excessiva d'aquest mot en un mitjà escrit podria ser conflictiva. 
gèneres diferents. I no, perquè la variable «diferents gèneres» afecta relativament poc el llenguatge col-loquial: certament, ho fa menys que la variable «diferents traductors» i molt menys que la variable «model de llengua col-loquial usat en traducció». Restriccions com la isocronia (en el cas del doblatge) o les limitacions de caràcters (en el cas dels subtítols) afecten la llargada del discurs meta, però molt poc, segons hem pogut comprovar, el llenguatge col-loquial que empren els traductors. Dit d'una altra manera: creiem que les traduccions col-loquials són diferents no només perquè les han fet traductors diferents, i no només perquè pertanyen a gèneres diferents, sinó (i sobretot) perquè el model de llengua col-loquial que s'hi utilitza és diferent en tots tres casos. Si el model de traducció col-loquial hagués estat el mateix en les tres traduccions, les discrepàncies, sovint profundes, que s'observen en el tractament del llenguatge col-loquial haurien quedat molt més llimades: el model de llengua col-loquial hauria unificat els trets col-loquials dels textos meta molt més del que ho estan. Això es veu clarament en els doblatges que encarrega TVC: els traductors i actors de doblatge s'han de cenyir a unes normes d'estil de la casa, de manera que diferents pel-lícules traduïdes per diferents persones acaben tenint un tractament lingüístic molt semblant i uniformitzador en tots els nivells, inclòs el del llenguatge col-loquial.

\section{LA COL·LOQUIALITAT DELS ORIGINALS I DE LES TRADUCCIONS: INTRODUCCIÓ}

Cal precisar, de bon principi, que el llenguatge col-loquial que analitzarem en aquest article és el que tècnicament s'anomena «col-loquial mediatizat», un terme encunyat pel grup Llengua i Mèdia (2004: 15). Segons Bassols (2009: I2),

\footnotetext{
De la mateixa manera que [el col-loquial mediatitzat] no s'identifica completament amb la llengua estàndard, tampoc no ho fa amb la llengua col-loquial. El col-loquial mediatitzat és el pseudocol-loquial dels textos orals o figuradament orals (escrits per ser llegits) més o menys espontanis.
}

El terme «col-loquial mediatitzat» es correspon amb el que en anglès anomenen fictive dialogue o fuctive orality, en castellà oralidad fingida o voz ficticia i en català «oralitat fingida».?

7. Sobre l'«oralitat fingida», vegeu Brumme \& Espunya (20I2), Brumme (2008), Brumme \& Resinger (2008), Brumme (2012) i Bartoll (20I2: 128). Per a una descripció dels principals trets fonètics, morfològics, sin- 
Dídac Pujol

Models de traducció literària $i$ audiovisual en català col-loquial

No és el nostre propòsit, pel que fa als originals en anglès (el guió i la pel-lícula), aturar-nos a fer una descripció més o menys aprofundida de la col-loquialitat, però sí que creiem convenient donar, breument i com a mostra, uns quants exemples de cadascun dels nivells de llenguatge (fonètica, morfologia, sintaxi i lèxic) on aquesta col-loquialitat es manifesta. Quant a la fonètica, l'anglès que s'hi utilitza té un dring clarament col-loquial: en comptes d'escriure Must have made Tarantino escriu Must of made (GO: 107), ${ }^{8} \mathrm{i}$ en comptes de having fun escriu havin' fun (GO: $\mathrm{I} 26$ ), uns respellings (o canvis ortogràfics) que són indicatius de la pronúncia que han de fer els actors i que coincideixen amb la pronúncia col.loquial que empren els personatges de la pel.lícula (VO: r:04:19 i i:18:09, respectivament). Pel que fa a la morfologia, sovint es recorre a la forma colloquial gonna en comptes de la forma estàndard going to (GO: 26; VO: o:15:49), o bé s'usa ain't en comptes de les formes estàndard am not / is not / are not $\mathrm{i}$ has not / have not (GO: 25; VO: 0:15:47). La sintaxi també té característiques col-loquials: en comptes de They don't want any trouble diuen They don't want no trouble (GO: 28; VO: 0:I7:59; doble negació); en comptes de Have you ever been tempted? s'hi usa Ever been tempted? (GO: I70; VO: I:35:34; omissió del verb auxiliar i del subjecte); i en comptes de this nigga hates cops es diu this nigga hate cops (VO: O:I6:I6; manca de concordança entre subjecte i verb a la VO, però no pas al GO, on s'utilitza una sintaxi estàndard). Finalment, en el cas del lèxic, és freqüent que bona part dels personatges (lladres i contrabandistes) utilitzin a tort i a dret vulgarismes com shit, ass i fuck (inclosos els compostos com motherfucker i els derivats com fucking).

Per acabar aquest apartat, oferim una breu pinzellada del català col-loquial que s'utilitza en les traduccions catalanes (el guió, el doblatge i la subtitulació) en cadascun dels nivells de llenguatge tractats en el paràgraf anterior. Val a dir que aquesta perspectiva general l'ampliarem, la matisarem i la discutirem a fons en els apartats 6, 7, 8 i 9. Ara,

tàctics i lèxics del català «col-loquial mediatitzat» (en oposició a la «llengua col-loquial» no mediatitzada), vegeu Bassols (2009: 13-18) i Paloma (2009); per a una diferenciació entre «estàndard oral» i «llengua oral» catalana, vegeu Bassols (2009: I8-20); sobre el "català estàndard» en els mitjans audiovisuals, vegeu Vallverdú (2000); per a una caracterització del «català col-loquial» —és a dir, del català no mediatitzat o "col-loquial real, el que s'utilitza fora de la pantalla» (Bladas 2009: 23) —, vegeu Payrató (1996) i Bladas (2009); i per a una descripció sumària de la llengua emprada en el doblatge de TVC, vegeu Santamaria (1997 i 2009).

8. D’ara endavant, utilitzarem les abreviatures següents: "GO» (= "guió original»); «GT» (= «guió traduït»), «VO» (= «versió original»); «VD» (= «versió doblada»); i «VS» (= «versió subtitulada»). Els números de després de «GO» $\mathrm{i}$ "GT» indiquen la pàgina; els de després de «VO», «VD» $\mathrm{i}$ «VS» indiquen el temps (hora, minuts i segons) que marca el cronòmetre del DVD. 
simplement, volem fer adonar el lector del fet que el llenguatge col-loquial anglès té, en general, una correspondència amb el llenguatge col-loquial català (en tots tres casos, pertanyent al dialecte del Principat de Catalunya anomenat "català central»). Pel que fa a la fonètica, el guió traduït, la versió doblada i la versió subtitulada reflecteixen la pronúncia col-loquial en casos com «Per 'xò» (GT: 19), «sisplau» (VS: I:II:25) i «io» (en comptes de «jo»; VD: o:05:40). La morfologia presenta alguns trets característics de la llengua col-loquial, per exemple el participi «sigut» en comptes d' «estat» (GT: I6I, VD i VS: I:58:IO) i contraccions pronominals com ara "conèixe'ns», "convènce'm» i «digue-li» (GT: 96, I33 i 169). De sintaxi col-loquial, en trobem mostres en alguns pleonasmes ("Ara li donaràs a la Sheronda una bossa», VS: I:30:00) i, sobretot, en la reducció de "per a» a "per», típica del català central («Saps perfectament que és per tu», GT: I5; "pels homes és diferent», VD i VS: 0:56:25). Finalment, el lèxic col-loquial es manifesta a través de formes no admeses al DIECI (I995), com per exemple «nòvia» (VD i VS: I:I2:42) o «làmpara» (GT: 69).

\section{MODELS I MODALITATS DEL CATALÀ COL'LOQUIAL: MAPA BIBLIO- GRÀFIC}

La bibliografia sobre el català col-loquial i les seves diferents modalitats (oral i escrita, literària, literària traduïda, audiovisual i audiovisual traduïda mitjançant doblatge o subtitulació) és molt abundant. El llibre general més complet sobre el català col-loquial és, sens dubte, el de Payrató (1996 [1988]). I els criteris més complets sobre el model de català col-loquial emprat per Televisió de Catalunya es troben a <http:// esadir.cat/gramatica/colloquial>. Hi ha, però, un munt d'estudis (i d'obres de creació literària) anteriors i posteriors a aquests dos treballs esmentats. A continuació, en mencionem i comentem (molt breument) només alguns, els que creiem més importants i els que (poc o molt) hem tingut en compte a l'hora de fer aquest estudi. La llista està ordenada per àmbits (relacionats amb les modalitats) i per ordre cronològic.

Pel que fa a l'estàndard oral i al català col-loquial (usats, per exemple, a la ràdio i a la televisió), són imprescindibles: Lacreu (2006 [1990]), un complet manual d'ús de l'estàndard oral valencià, aplicable en bona part a la resta del domini lingüístic català; el pioner llibre d'estil de Televisió de Catalunya (1995); el primer estudi sistemàtic i de conjunt de la llengua de TV3, Bassols, Rico i Torrent (1997); les reflexions 
Dídac Pujol

Models de traducció literària i audiovisual en català col-loquial

de Vallverdú (2000) sobre aspectes lingüístics puntuals de l'estàndard de TV3, que matisen o completen les directrius del llibre d'estil de Televisió de Catalunya (1995); Bassols \& Segarra (2009), un estudi sobre el registre colloquial en els mitjans de comunicació contemporanis, sobretot la televisió, però també la ràdio; Corporació Catalana de Mitjans Audiovisuals (2013), la versió ampliada i actualitzada del llibre d'estil de Televisió de Catalunya (1995); i Gifreu (20I4), un estudi sociològic sobre el desplegament i l'evolució del català (inclosa l'estandardització i els diferents models de llengua) en els mitjans de comunicació des de la Transició espanyola fins a l'actualitat.

Sobre el model de traducció i de doblatge de Televisió de Catalunya, són essencials: Comissió de Normalització Lingüística TVC (1993), precursor de les orientacions lingüístiques per al doblatge de Televisió de Catalunya (1997); Televisió de Catalunya (1997), evolució de l'obra esmentada anteriorment; Izard Martínez (1999), sobre la traducció audiovisual i la creació de models de llengua en una sèrie francesa doblada al català; i el portal lingüístic de la Corporació Catalana de Mitjans Audiovisuals Es a dir (<http://esadir.cat>, evolució de Televisió de Catalunya 1997, i actualitzat permanentment). En l'àmbit general, també val la pena esmentar les obres següents, que, malgrat que tenen un caràcter posterior respecte a les traduccions de Jackie Brown, il.luminen certs aspectes de la pràctica del doblatge i de la subtitulació. Es tracta de: (I) els criteris de subtitulació del portal lingüístic És a dir (<http://esadir. cat/entrades/fitxa/node/Subtitulacio_criteri_linguistics>); (2)l'obra, pionera en català, de Frederic Chaume Doblatge i subtitulació per a la TV (2003); (3) Llengua i Mèdia, La subtitulació del col.loquial (2004); (4) Consell de l'Audiovisual de Catalunya (2007), un monogràfic sobre la qualitat de la llengua en els mitjans audiovisuals; (5) Grup Flaix (comp.), Diccionari del català col-loquial. Dubtes davant del micròfon (2009), uns criteris lingüístics per als locutors de ràdio del grup d'emissores Flaix; i (6) Eduard Bartoll, La subtitulació. Aspectes teòrics $i$ pràctics (20I2, especialment l'apartat 7.2.I, pp. I60-I66, titulat: «Estratègies per a restituir l'oralitat de l'escrit»). Per a una anàlisi de la influència dels patrons prosòdics, rítmics i entonatius anglesos i castellans en el doblatge al català de $\mathrm{TV}_{3}$, un àmbit que queda fora del nostre objecte d'anàlisi, vegeu Forcadell (2OI2, 2013).

El català literari modern té l'inici fundacional amb Jacint Verdaguer (Bibiloni, Castellanos \& Marquet 2006; Pinyol \& Quer 2006) i continua amb els escriptors modernistes. Però serà Pompeu Fabra (Lamuela \& Murgades 1984), amb l'ajut dels escriptors noucentistes, sobretot del Carner traductor (Cabré \& Ortín 1984; Toutain 
1997; Feliu 2008), qui forneix les bases per a la construcció d'un català literari modern, projecte que culminarà amb les obres de Josep Pla, Mercè Rodoreda i Salvador Espriu (vegeu Pericay \& Toutain 1996). Centrant-nos en el llenguatge literari col-loquial, al llarg dels segles xx i XxI trobem obres de creació amb un fort component col-loquial, des de les novel.les de Juli Vallmitjana (La Xava, I9IO), passant pel teatre de Salvador Espriu (Primera història d'Esther, 1948), fins arribar a les novel-les d'escriptors contemporanis com Ramon Solsona (Figures de calidoscopi, I989; L'home de la maleta, 201I) i Marta Rojals (L'altra, 20I4). Totes aquestes obres responen a models de llengua diferents, fruit, sobretot, de la voluntat dels autors de reflectir el (o un) llenguatge col-loquial d'una determinada època, però també de la voluntat d'aquests escriptors de crear(-se) un llenguatge literari col-loquial. En el camp de la traducció, trobaríem obres en què abunda el llenguatge col-loquial, per exemple l'adaptació lliure del Pigmalió de George Bernard Shaw feta per Joan Oliver (1957), passant per El vigilant en el camp de sègol de J. D. Salinger (traducció d'Ernest Riera i Josep M. Fonalleras, 1990), fins arribar a traduccions contemporànies com Agost de Tracy Letts (traducció de Joan Sellent, 20IO). Evidentment, el que hem dit dels escriptors s'aplica als traductors: aquestes obres reflecteixen el (un) llenguatge col-loquial d'una determinada època, però també el creen. I ja en un altre àmbit, el musical, trobaríem cançons que utilitzen el llenguatge col-loquial que es parla avui dia: vegeu, per exemple, la cançó "Juerga catalana» d'Albert Pla (2008), on al costat d'alguns castellanismes (bassura) hi trobem formes catalanes col-loquials genuïnes però no normatives («vem» en comptes de «vam»).

\section{MODELS I MODALITATS DEL CATALÀ COL·LOQUIAL ALS ANYS 1990 I AL 1997-1998: MAPA BIBLIOGRÀFIC}

El català col-loquial ha estat, històricament, una font de discussions i de problemes a l'hora de traslladar-lo a la pàgina escrita $\mathrm{i}$ als mitjans audiovisuals com la ràdio, la televisió, el teatre i el cinema. El debat arrenca amb les obres de teatre de Frederic Soler, conegut amb el pseudònim de "Serafí Pitarra» (I839-I895). Pitarra utilitza el que ell anomena "català que ara es parla»," és a dir, el català del carrer, contaminat

9. Pitarra descriu la seva obra Singlots poètics (I864) així: «Singlots poètics, o sigui, col-lecció de totes les obres que, en vers i en català del que ara es parla, ha escrit don Serafí Pitarra» (Pitarra 20I4: I, 2I). 
Dídac Pujol

Models de traducció literària i audiovisual en català col-loquial

de castellanismes, per oposició al català més depurat (però també més encarcarat i arcaïtzant) que pretenien recuperar els fundadors dels Jocs Florals, Antoni de Bofarull (I82I-I992) i Víctor Balaguer (I824-I9OI).

No va ser fins als anys 1980 que es va plantejar el problema de quina mena de català oral calia fer servir en els mitjans de comunicació audiovisuals, és a dir, a Catalunya Ràdio i a TV3, nascuts, respectivament, el 20 de juny de 1983 i el Io de setembre de 1983. La vella polèmica del "català que ara es parla» va revifar (vegeu Tubau 1990), aquest cop amb el nom de "català light», que s'oposava a l'anomenat "català heavy» propugnat pels més puristes i per l'Institut d'Estudis Catalans. La polèmica entre català heavy i català light va tenir lloc a la dècada dels 1980 i a principis dels 1990 — sobre el tema, vegeu Pericay \& Toutain 1986, Pazos 2007 (Ia edició, 1990), Tubau 1990, Sabater 199I, Grup d'Estudis Catalans 1992, Institut d'Estudis Catalans I996a i 1996b (Ia edició, 1990 i 1992) i Kailuweit 2002. Sense entrar en detalls, podem concloure que, vist amb perspectiva, el model de llengua oral que es va acabar imposant als anys 1990 (i que, evolucionat, encara perdura) en els mitjans de comunicació esmentats va ser el «català light», o si més no una forma no gaire castellanitzada de «català light», un català que difereix del català estrictament normatiu i que no està exempt de polèmica: Joan Sellent, per exemple, parla del «català ortopèdic que sovint ens ofereixen els mitjans de comunicació» (20I4, i també en aquest volum), i Narcís Garolera, referint-se també als mitjans de comunicació (diaris, ràdios i televisions públiques i privades) a la Catalunya del segle XXI, denuncia dos fets: (I) que «fan servir un català que cada vegada és més un calc del castellà» (20I4: 175); i (2) que mostren «un desconeixement de les possibilitats expressives de l'idioma (sobretot de les formes vives i populars)» (2014: $175-176)$.

Centrant-nos en l'època en què es va doblar i traduir Jackie Brown, és a dir, finals de 1997 i principis de 1998, cal dir que, a banda dels textos analitzats (doblatge, subtítols i guió escrit), per a l'estudi dels models de llengua col-loquial ens hem valgut de diverses eines que ens han permès viatjar en el temps i contextualitzar els productes objecte d'anàlisi. Es tracta de: (I) el primer llibre d'estil de TV3, eina importantíssima per a redactors, locutors i dobladors: Televisió de Catalunya, El català a TV3. Llibre d'estil (març de 1995); (2) el primer diccionari normatiu (si més no contemporani) de l'Institut d'Estudis Catalans, el DIECI (Diccionari de la llengua catalana, setembre de 1995), que va actualitzar el Diccionari general de la llengua catalana de Pompeu Fabra, establint de manera clara quins eren els mots admesos per la normativa i quins no; (3) 
Televisió de Catalunya, Criteris lingüistics sobre traducció i doblatge (gener de 1997), la primera eina de conjunt que dictamina quins són els criteris pels quals s'han de guiar els traductors i dobladors de $\mathrm{TV}_{3}$; (4) el primer estudi de conjunt de la llengua de TV3: Bassols, Rico \& Torrent (eds.), La llengua de TV3 (març de 1997); (5) un llibre d'anàlisi sociolingüística: Joan Pujolar, De què vas, tio? (setembre de 1997), que estudia els diversos parlars juvenils contemporanis, prestant especial atenció a l'alternança entre català i castellà i a l'argot català, sovint d'origen castellà; (6) l'únic recull lexicogràfic que retrata la llengua col-loquial durant els anys 1990: Joaquim Pomares, Diccionari del català popular i d'argot (octubre de 1997); (7) dues obres de l'Institut d'Estudis Catalans pensades per orientar els professionals dels mitjans audiovisuals (Catalunya Ràdio i TV3) nascuts set anys abans: Proposta per a un estàndard oral de la llengua catalana. I Fonètica (1990 i za edició revisada, juny de 1996) i Proposta per a un estàndard oral de la llengua catalana. II Morfologia (I992 i za edició revisada, juny de 1996$) ;{ }^{10}$ i (8) una tesi doctoral que analitza els models de llengua col-loquial en el doblatge de TV3 de mitjan anys 1990: Natàlia Izard Martínez, Traducció audiovisual i creació de models de Ilengua en el sistema cultural català. Estudi de cas del doblatge d'Helena, quina canya!' (setembre de 1999). ${ }^{11}$ Aquestes obres, tant si han estades esmentades o citades explícitament com si no (la majoria ho han estat), ens han permès submergir-nos, sense caure en la visió anacrònica pròpia d'un observador actual, en els models de llengua oral i col-loquial que imperaven a l'època en què es va traduir Jackie Brown.

\section{JACKIE BROWN: LA FONÈTICA}

En aquest apartat $\mathrm{i}$ en els següents $(6,7,8 \mathrm{i}$ 9) descriurem, analitzarem i compararem els diferents nivells de llenguatge (fonètica, morfologia, sintaxi i lèxic) pel que fa

IO. D'aquestes dues obres de l'IEC hem utilitzat, respectivament, les edicions revisades del juny de 1996, publicades en paper. La za i 4a edició revisades (sobre fonètica i morfologia respectivament) són del juny de 1998, és a dir, uns mesos posteriors a la data de la traducció i del doblatge de Jackie Brown, i per tant no s’han tingut en compte.

II. Tot i que l'obra d'Izard Martínez és de 1999, i per tant posterior al doblatge, la subtitulació i la traducció del guió de Jackie Brown (1997-1998), l'hem presa en consideració perquè se centra en els models de llengua col-loquial de mitjan anys I990: concretament, l'obra estudia el doblatge de la sèrie Hélène et les garçons, que TVC va emetre amb el títol Helena, quina canya! entre gener i novembre de 1994 i entre gener i juliol de I996 (Izard Martínez 1999: I28). 
Dídac Pujol

Models de traducció literària i audiovisual en català col-loquial

al model de traducció col-loquial, tant en la modalitat escrita (guió traduït en format de llibre) com en la modalitat audiovisual (doblatge i subtitulació). Hem cregut que era millor tractar conjuntament els nivells de llenguatge que fixar-nos ailladament en les diferents modalitats: d'aquesta manera es fan més evidents els contrastos entre els models de traducció col-loquial.

La fonètica és un nivell de llenguatge que, necessàriament, es veu reflectit en el doblatge, però que costa molt més d'apreciar (si és que es pot apreciar) en la subtitulació i en el guió traduït, atès que aquestes últimes modalitats se solen basar en la forma escrita de les paraules, ja determinada per la normativa. Sigui com sigui, en la versió subtitulada trobem «sisplau» (I:Ir:25), un dels poquíssims casos de subtitulació en què l'ortografia reflecteix la pronúncia habitual col-loquial dels parlants, en comptes de la forma "si us plau», molt menys habitual i certament més formal. Un altre cas de llenguatge col.loquial en la subtitulació és l'ortografia «peli» (0:05:03) en comptes de «pel-li» (truncament de "pel-lícula»).

En el cas del guió traduït, la traductora ha introduït diversos canvis ortogràfics (el que en anglès en diuen respellings) per tal de reflectir que ens trobem davant d'un text col-loquial. Podem agrupar els mecanismes de canvi ortogràfic en diversos tipus: assimilació, epèntesi i elisió.

L'únic cas d'assimilació que hem trobat és «endivina» (p. 35), mentre que d'epèntesi n'hem trobat un parell de casos: «No en tinc ni ideia» (p. 35) i la forma «érets» en comptes de la normativa «eres» (pp. 94 i 95: «Érets una noia de discoteques?» $\mathrm{i}$ «Érets un noi de discos, tu?»). El fenomen de l'elisió és, en canvi, molt més habitual.

D'elisions, en podem distingir dos grans grups: elisions fonètiques dins d'un mot i elisions que pertanyen a l'àmbit de la fonètica sintàctica. Del primer grup, en són exemples «ja vuràs» (p. I4), «Re» / "per re és això el que estic dient» (pp. I7 i Ioo) $\mathrm{i}$ «hem sortit a fer un volt, 'nàvem a [...]» (p. 2I), al costat de casos una mica més agosarats com «tranquil.litza't, cony. 'Ns veiem demà» (p. I9) i «Ell diu qu' és com si uastiguéssiu [, de casats]» (p. in6; la cursiva és nostra). Val a dir que en determinades formes s'observa una variació, no pas atribuïble a diferents nivells de llenguatge utilitzats pels personatges, sinó a incoherències per part de la traductora del guió: així, trobem "pendre [una beguda]» (p. 2I) / "prendre'm la molèstia» (p. 42), "Ja casi estem» (p. 24) / «quasi vint anys» (p. 82).

En el guió traduït, la majoria de casos d'elisió pertanyen a l'àmbit de la fonètica sintàctica, i són deguts al contacte entre vocals de diferents mots, per exemple «Per 
'xò els paguen» (p. 19), «He 'nat al cinema» (p. IO5), «no 't preocupis» (p. 2I), «No 's [= has] de fer re» (p. 24) i «Tio, 'quest trasto val una pasta» (p. I4). En aquest últim cas, cal remarcar que la grafia «s» del mot «aquest» no s'ha elidit, cosa que contrasta, a la mateixa frase, amb l'elisió de la «a» d'«aquest» mitjançant un apòstrof (o coma volada). Val a dir que al llarg de tot el guió traduït l'apòstrof s'usa només per indicar elisió fonètica sintàctica ("He 'nat»), però no pas per indicar elisió fonètica dins un mot («ja vuràs»). Això s'explica pel fet que en català l'apòstrof només es fa servir per indicar elisió entre dos mots. Sigui com sigui, en la traducció del guió l'apòstrof que indica col-loquialitat no normativa va (de dalt a baix) en direcció dreta, quan segurament hauria estat més lògic utilitzar l'apòstrof típic català, que va (de dalt a baix) en direcció esquerra (així, hauria estat desitjable escriure "per 'xò» i no pas «per'xò»).

Passem ara a analitzar la versió doblada. Com hem dit al principi d'aquesta secció, és lògic que la fonètica col-loquial es vegi reflectida sobretot en el mitjà oral (doblatge) i molt menys en l'escrit (subtitulació i guió traduït). No pretenem, aquí, fer una anàlisi exhaustiva de la fonètica del doblatge català de Jackie Brown, però sí donar-ne els trets principals. En primer lloc, cal dir que hi ha un predomini absolut de la pronúncia del català central, cosa que contrasta amb l'original anglès, on els personatges de raça negra parlen amb trets fonètics típics d'aquesta comunitat. I, en segon lloc, podem afirmar, coincidint amb Santamaria (1997: 90), que el doblatge segueix els criteris de pronunciació exigits per $\mathrm{TV}_{3}$ en les sèries de producció aliena, és a dir: es dóna preferència a l'estàndard oral de l'IEC (Institut d'Estudis Catalans 1996a, fixat ja l'any 1990). Alguns dels casos més representatius són:

(I) pronunciació de la $e$ final com a vocal neutra al final de mots com «frase» o «classe» (IEC I996a: 17): «primera classe» (o:03:30);

(2) pronunciació de l'essa sorda en tots els casos (IEC 1996a: 19): «m’ha impressionat» (0:07:07).

Tant en el cas (I) com en el (2) és força habitual que la pronúncia col-loquial sigui diferent de la recomanada per l'IEC, que és la que trobem en la versió doblada (VD). Altres pronúncies, en canvi, no sobten tant com les anteriors, atès que en aquest punt l'IEC i la VD coincideixen amb la fonètica col-loquial dels parlants:

(3) iodització de mots com «jo» i «ja» (IEC I996a: 19): «ia saps que» (o:06:20);

(4) elisió en casos de fonètica sintàctica (IEC i996a: 22): «que era aquí»/kéra kí/(I:48:48); 
Dídac Pujol

Models de traducció literària i audiovisual en català col-loquial

(5) elisió de la primera $r$ del verb «prendre»: «A pendre pel cul»(O:I2:I8). En el cas d'aquest verb, l'IEC diu que són pròpies de l'àmbit general tant les pronúncies amb $r$ com les sense $r$ (IEC I996a: 2I).

Tot i que hem vist que la pronúncia generalitzada en el doblatge és la que recomana l'IEC en la seva proposta d'estàndard oral, hi ha certes pronúncies que l'IEC desaconsella però que, en canvi, ocorren en el doblatge. El motiu és simple: es tracta de donar versemblança a la fonètica per tal que el discurs no soni excessivament formal. La principal forma «no recomanable» (en terminologia de l'IEC) és la caiguda de $a$ o e per contacte amb r (IEC I996a: I6): "La v'ritat és que no hi penso gaire» (0:56:05).

En alguns casos, en la VD trobem alternança de formes. La primera que donem (6a, 7a) és la més formal, i està explícitament recomanada per l'IEC (I996a), mentre que la segona $(6 \mathrm{~b}, 7 \mathrm{~b})$ és més informal i (en casos com el de $7 \mathrm{~b}$ ) està explícitament desaconsellada per l'IEC:

(6) pronúncia de $t l l / t$ en mots com ratlla o bitllet (IEC i996a: 20):

(6a) «repeteix els rotllos que sent» [rótllus] (o:07:IO);

(6b) «rotllo» [róllu] (o:15:39);

(7) pronúncia de $l \cdot l / l$ (IEC i996a: 20):

(7a) «la cel.la» (ús esporàdic en la VD);

(7b) «milímetres» (0:05:23), «película» (0:05:03), «en metàlic» (o:40:44) (ús habitual en la VD).

Hi ha casos que l'IEC no menciona i que en la VD s'opta per pronunciar de manera formal. Així, en la VD el mot "compte» («em surt a compte») es pronuncia «comte» (0:I5:45) en lloc de «conte», i el mot «explicar» es pronuncia majoritàriament «explicar» (0:I6:IO, I:05:44, I:59:48) i només esporàdicament «esplicar» (I:04:53). D’altra banda, trobem casos que l'IEC no menciona i que en la VD s'opta per pronunciar de manera col-loquial, per exemple «déu» en comptes d' "adéu» $\mathrm{i}$ «què» en comptes de «que» («M'has entès el què t'he dit, fill de puta?», 0:49:I8).

Hem observat que, pel que fa a la pronúncia, la VD és més conservadora que el guió traduït (GT): formes com «endivinar» o "érets», que hem vist que ocorren en el GT, són impensables en la VD, que té sobretot en compte els fenòmens de fonètica sintàctica, com "per 'xò» (VD: 0:42:I8). Hi ha, això sí, un mot que contrasta marca- 
dament amb la pronúncia que reflecteix el GT. Es tracta de «res» (VD: 0:05:27) / «re» (GT: IOO). En el GT la forma utilitzada sistemàticament és «re», mentre que en la VD la pronúncia habitual és «res»; només n'hem trobat una excepció, curiosament a la mateixa frase: «I tu no els vas contestar res de re?» (VD: 0:48:27).

Finalment, sobta (per l'alta freqüència d'ús en la pel-lícula) que en la VD es pronunciï «Mèxic» com a "Mècsic», quan la pronunciació popular ha estat, almenys tradicionalment, «Mègic» (Garolera 20I4: I8I, n. 25).

\section{JACKIE BROWN: LA MORFOLOGIA}

La morfologia del guió traduït (GT) s'ajusta molt a la normativa. Així, s'escriu «en volem dues» (p. I4), quan l'IEC (I996b: 2I) dóna com a «admissible» tant «dues» com la forma invariable (i menys formal) «dos», i quan també s'hauria pogut utilitzar la forma col-loquial «dugues». En aquest cas, el GT ha optat per «dues», l'opció més formal i, també, la menys marcada lingüísticament.

En altres casos, però, s'opta per la variant més informal, ja sigui per la forma castellana «lo» en comptes d' «allò» («Parlaven en sèrio de tancar-me per lo de les armes», p. 28), ja sigui per la forma «sigut» en comptes d' «estat» («ha sigut la Jackie Brown", p. I6I), ja sigui per una forma pronominal reduïda en comptes d'una forma plena, per exemple «'Nem a conèixe'ns» (p. 96) en lloc de "Nem a conèixer-nos» i «Ha intentat convènce'm» (p. 133) en comptes d' «Ha intentat convèncer-me». Val a dir que les formes pronominals reduïdes i la forma «sigut» estan admeses tant en la proposta d'estàndard oral de l'IEC (I996b: 23 i 3I) com en els Criteris lingüistics sobre traducció i doblatge de Televisió de Catalunya (1997: 33-34 i 35).

Només en alguns casos trobem desviacions de la normativa que acosten la llengua del GT a la de la parla col-loquial: és el cas de «digue-li» (p. I69) en comptes de «digues-li», forma no recollida per l'IEC (I996b), i del subjuntiu «estés» («també podria ser que ella l'estés analitzant amb la mirada», p. 73), que l'IEC qualifica de "no recomanable» (1996b: 42). En aquest últim cas, cal notar que la forma col.loquial apareix en una acotació escènica, cosa que contrasta amb l'ús estàndard de la llengua que es fa en les acotacions del guió original anglès. Ocorren també dins d'acotacions

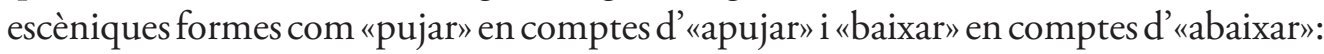
«L'Ordell puja el volum» (p. I4), "La Jackie [...] baixa la cremallera de la bossa» (p. 47). 
Dídac Pujol

Models de traducció literària i audiovisual en català col-loquial

Finalment, pel que fa al GT, s'observa que hi ha una alternança entre el masculí i el femení per referir-se a noms de professions. Així, al costat dels noms «una xèrif» (p. 6o, dos cops) $\mathrm{i}$ «Les xèrifs» (p. 50), trobem les formes femenines «Una xèrifa» (p. 49) i «la xèrifa» (p. 60). En aquest cas, la normativa era molt clara l'any en què es va traduir Jackie Brown: el femení de "xèrif» és "xèrifa", segons el DIECI (I995). Podem concloure doncs, que les vacil.lacions en l'ús de la forma femenina del nom són, probablement, causades pel desconeixement de la normativa.

La morfologia de la versió subtitulada (VS) i de la versió doblada (VD) no és gaire diferent de la del guió traduït (GT). Com en el GT, en la VD i en la VS es fa servir el participi «sigut» en comptes d' «estat»: «ha sigut la Jackie Brown» (VD i VS: I:58:IO), «Ha sigut divertit» (VS: I:05:IO). Aquest és, en realitat, l'únic tret morfològic col-loquial que comparteixen els diferents textos meta (GT, VD i VS). La morfologia de la VD i de la VS, de fet, és molt normativa, i en cap moment hi trobem formes col-loquials com «aixins", «aviam», «radere»; en comptes d'això, hi trobem els seus equivalents normatius "aixi”", «a veure» $\mathrm{i}$ «darrere» (VD: 0:05:36, o:28:53 i o:49:35). Igualment, com en el GT, en la VD i en la VS s'utilitza la forma «dues» en comptes de les més informals «dos» o «dugues»: «Faig dues entregues» (VD: I:08:22), «Faig dues trameses» (VS: I:08:22). Això sí: davant de la possibilitat de triar entre dues formes recollides al DIECI (I995), la VD opta per la més col-loquial: «No compro gaires novetats» (o:53:29) en comptes de «[...] gaire novetats». En l'ús dels pronoms, tant la VD com la VS són més formals que el GT, que — com hem vist— fa servir formes pronominals reduïdes com "conèixe'ns» (p. 96). Així, en la VS les formes plenes com «-los», «-vos», etc. són les úniques que trobem. La VD, en canvi, procura no fer un ús sistemàtic d'aquestes formes pronominals (que en un text informal poden sobtar determinats espectadors) i les alterna amb pronoms anteposats al verb, per exemple «I com ens pot ajudar?» (VD: 0:59:20), en contrast amb «Com pot ajudar-nos?» (VS: 0:59:20), o "Ens en podríem quedar els que volguéssim» (VD: I:36:09), que contrasta amb «Podríem quedar-nos amb els que volguéssim» (VS: 1:36:09). Sigui com sigui, la morfologia de la VD i de la VS és, en general, rígida, fins i tot més que la del GT: mentre que aquest últim presenta algunes desviacions respecte a la normativa («digueli», «estés»), la VS no en presenta cap, i la VD només una, el verb «enfotre's»: «Al jutge se li enfot una merda, això» (VD: o:Io:Io). Aquest cas, ben esporàdic, no és suficient per crear una llengua en què abundin els fenòmens de morfologia col-loquial: tots tres textos meta brillen per l'absència de formes collloquials com «vem» (= «vam»), 
«poguer» (= «poder»), «sapiguer» (= «saber»), «escolleixo» (= escullo), «llàpissos» $(=$ «llapis») o «eleganta» (= «elegant»).

\section{JACKIE BROWN: LA SINTAXI}

La sintaxi del guió traduït (GT) presenta quatre característiques destacades: la col-loquialitat, la formalitat, la castellanització il'anglicització. Quant a la col.loquialitat, un dels trets més destacats és l'ús no normatiu, però ben col-loquial, de la combinació "els hi»: "Ja els hi diré que l'obro» (p. 3I) en comptes de "Ja els diré que l'obro», o bé «Però ja els hi vaig dir» (p. 57) en comptes de «Però ja els ho vaig dir». La forma «els hi» s'usa de manera coherent al llarg de tot el GT, de manera que trobem fins i tot frases en què aquesta combinació pronominal ocorre dos cops: «Els hi encanta pensar que els hi té por» (p. I34).

L'ús col-loquial d' «els hi» que hem vist en el paràgraf anterior coexisteix i contrasta amb trets propis de la sintaxi formal, cosa que no s'adiu amb la sintaxi col-loquial del guió original i que, sobretot, crea un xoc de registres en el text meta. Heus ací alguns exemples representatius dels contrastos sintàctics que es poden observar en el GT:

(I) «viu en un apartament [...] del qual ell surt $i$ hi entra quan vol» (p. 13);

(2) «Jo els hi diré que l'obro per ensenya'ls [sic] la mercaderia» (p. 3I);

(3) «Per 'xò li’n diuen "fotre el personal”" (p. 28); «Són molts diners. Mig milió, i encara li n'han d'arribar més» (p. 80);

(4) «El Beaumont treballava per a tu» (p. 57); «Voldran saber si treballava per mi» (p. 57).

A l'exemple (I), una acotació escènica (per això apareix en cursiva), la sintaxi formal («del qual») contrasta amb el pleonasme no normatiu "hi entra». Aquesta incoherència és atribuible, segurament, al poc domini de la llengua de la traductora. L'exemple (2) és estrany. Per aconseguir un efecte col-loquial, hauria de ser «Jo els hi diré que l'obro per ensenyàls-hi la mercaderia»: d'una banda, caldria afegir-hi el pronom «-hi», i de l'altra caldria posar un accent a «ensenya'ls» per tal que la pronunciació fos «ensenyàls». A (3) observem un encarcarament, perfectament normatiu però gens col.loquial, en les combinacions de pronoms febles: en el primer exemple sobta el contrast entre una ortografia que representa la fonètica col.loquial ("Per 'xò») i una combinació pronominal que no ho és gens, de col-loquial. En aquest cas, «li’n» 
s'hauria pogut substituir perfectament per una combinació menys marcada, «n'hi»: "Per 'xò n'hi diuen "fotre el personal"». La mateixa rigidesa (pròpia d'un text formal) la trobem al segon exemple, en què la combinació pronominal més col-loquial hauria estat «encara n'hi han». Finalment, s'observa al llarg de tot el guió l'ús predominant de "per» en comptes de "per a", però ocasionalment apareix "per a»; aquest contrast es pot observar en els dos exemples de (4), en què la incoherència en l'ús de "per» i "per a» sobtarà de ben segur el lector.

El model de llengua emprat en el GT és, a més de colloquial i (a vegades) formal, castellanitzat i (de vegades) fins i tot anglicitzat. Els exemples següents són calcs de la sintaxi castellana:

(5) «Passaràs la nit al trullo, ara és massa tard per treure't» (p. 19);

(6) «I això què cony té a veure?» (p. 98);

(7) «Obre el paquet de Mild Seven's i li ofereix un al Max» (p. 63);

(8) «Em jugo algo a que era el regal que [...]» (p. 70);

(9) «Ja se’t passarà» (p. I82);

(ı) «Coneixies a Mr. Walker, ¿̨oi?» (p. 130).

A l'exemple (Io) s'utilitza, per influència del castellà, la preposició «a» per introduir el complement directe. La resta d'exemples, del (5) al (9), tenen a veure amb un mal ús dels pronoms influït per la sintaxi castellana. Així, a (5) hi hauria de dir «[...] per treure-te'n». Cal fer constar que el pronom «en» apareix tan aviat sí com no, sense gens de coherència, de manera que al cap de poca estona de llegir la frase (5) trobem aquesta altra, escrita amb el pronom «en»: «Passaràs la nit al talego, però ja t'he dit que te'n treuré $[$ sic] demà» (p. 20). L'exemple (6), com el (5), presenta un calc de la sintaxi castellana, que no té pronoms febles: aquest cop s'omet «hi», quan s'hauria d'haver escrit «I això què cony hi té a veure?». L'exemple (7) calca l'estructura pronominal castellana le ofrece uno a Max; l'exemple (8) calca a que (Apuesto algo a que [...]); i l'exemple (9) utilitza el pronom «se» per influència del castellà.

Pel que fa al GT, hem de dir finalment que també presenta interferències de la sintaxi anglesa: la traductora calca l'estructura juxtaposada anglesa (dues frases separades per comes) en comptes d'unir les frases mitjançant coordinació. En donem dos exemples representatius, seguits de la frase que apareix en el guió anglès i de la solució que hauria estat òptima: 
(II) «L'assassí tenia una .45, ells volen una .45» (p. I4); The killer had a .45, they want a .45 (p. 7); «L'assassí tenia una .45 i ells volen una .45 [tant sí com no]»;

(I2) «Jo pago la teva fiança, ells et deixen fotre el camp» (p. I9); I pay your bail, they gonna cut you loose (p. I3); "Jo et pago la fiança i ells et deixaran fotre el camp».

Passem ara a analitzar la sintaxi de la versió doblada (VD) i de la versió subtitulada (VS). A grans trets, podem dir que la sintaxi del GT és la més col-loquial de totes, mentre que la de la VS és la més estàndard. La VD es troba entremig. En general, tant la VD com la VS utilitzen «per» en comptes de «per a», tot i que molt puntualment la VS fa servir "per a»: "voles per a la companyia mexicana» (o:29:30). Tant la VD com la VS presenten una característica col-loquial que també ocorre en el GT: els pleonasmes. En donem un exemple, dels diversos possibles, en les tres modalitats: «me n'estic adonant de qui són els meus amics» (GT: I67), «No li has agafat mai el cotxe a ningú?» (VD: 2:19:23) i "Ara li donaràs a la Sheronda una bossa» (VS: I:30:00). Val a dir que els pleonasmes són força més habituals en el GT i en la VD, mentre que en la VS ocorren poc.

Per acabar l'anàlisi de la VD i de la VS, ens centrarem en dos punts: l'absència de la combinació pronominal «els hi» i la combinació «des que». Tots dos fenòmens contribueixen al fet que la sintaxi de la VD i de la VS soni poc col-loquial. Pel que fa a «els hi», en el GT ocorre amb molta freqüència, tant si el pronom «hi» no té cap funció sintàctica ("Jo els hi diré que l'obro», p. 3I) com si substitueix el pronom «ho» en funció de complement directe («Els hi he dit jo», p. 97). En canvi, «els hi» no apareix ni a la VD ni a la VS, excepte quan la combinació és normativa, per exemple a «tu i io els hi prenem [els diners a ella]»(VD: I:Ir:56). En la resta de casos, que són la gran majoria, en la VD i en la VS s’utilitza el pronom sense substituir-lo per «hi» («No calia que els ho confirmessis», VD: I:07:34) i sense combinar-lo amb «hi»: "I què els vas dir?» (VD: 0:46:52), «I què els vas contestar?» (VS: 046:52), «Els he dit» (VD: I:08:35).

\section{JACKIE BROWN: EL LÈXIC}

La principal característica del guió traduït (GT) és la profusió, la majoria de vegades volguda, de castellanismes, que hem classificat en diversos tipus: (I) castellanismes explícitament qualificats com a «no admissibles» per $\mathrm{TV}_{3}$ al seu portal lingüístic És a dir (<http://esadir.cat>); (2) castellanismes d' «ús restringit», segons TV3; (3) 
Dídac Pujol

Models de traducció literària i audiovisual en català col-loquial

mots d'origen castellà o amb una accepció d'origen castellà admesos al DIECI; (4) mots amb una accepció d'origen castellà no admesos al DIECI però sí al DIEC2; i (5) castellanismes que no figuren en cap dels grups anteriors i que pretenen donar un to col-loquial al text. Val la pena deixar clar que, en aquest apartat, ens centrem sobretot en els castellanismes, atès que aquest és l'aspecte més sorprenent i el que més polèmica ha generat entre els partidaris del "català heavy» i els del "català light» (vegeu l'apartat 5). Tot amb tot, abans de prosseguir cal deixar ben clar que els castellanismes no són l'únic recurs lèxic col-loquial; en les traduccions hi ha altres mecanismes (alguns dels quals també transgredeixen la normativa) que s'utilitzen per denotar col-loquialitat. En destaquem les categories següents:

(6) lèxic i locucions col-loquials: «mam» en comptes de «beguda» (VS: 0:45:40), «Li queda la mar de bé [el vestit]» (VD: r:40:50) i «Et queda de conya» (VD: r:4I:33);

(7) llenguatge vulgar normatiu: «Hòstia puta!» (GT: 70);

(8) llenguatge vulgar genuí però no normatiu: «Cagundena» (VS: o:46:32); i

(9) truncaments: «polis» en comptes de "policies» (GT: 74).

Centrant-nos en els castellanismes, al llarg del GT s'utilitzen mots explícitament qualificats com a «no admissibles» al portal lingüístic de la Corporació Catalana de Mitjans Audiovisuals És a dir. Es tracta dels mots «apretar» (p. 24), «enterar-se» («Se'n va enterar», p. 7I; «no s'entera de re», p. I2I) i «alevosia» (en l'expressió «amb premeditació i alevosia», p. I8I), mot que l'És a dir recomana substituir per "traïdoria». D'altra banda, en el GT hi ha castellanismes que TV3 etiqueta com d' «ús restringit», és a dir, mots que admet només en contextos col-loquials: "cutre» (p. II), "tonta» (p. 84), «bolso» (p. I23) «trullo» (p. 19) i «talego» (p. 20). ${ }^{12} \mathrm{Hi}$ ha, encara, mots d'origen castellà ("guapo», p. 75) o amb una accepció d'origen castellà ("follar» en l'accepció de «fer l'acte sexual», p. 95) que estan admesos al DIECI (I995), i que per tant ja eren normatius en el moment en què es va publicar la traducció. A més, en la traducció hi ha un mot ("cabró») amb una accepció d'origen castellà que no està admès al DIECI (I995) però sí al DIEC2 (2007): «El molt cabró m’ha penjat!» (p. I67).

El gruix de castellanismes, però, pertany a la cinquena categoria esmentada anteriorment. Són castellanismes que no figuren en cap dels grups anteriors i que pretenen donar un to col-loquial al text. En donem una petita mostra (sovint acom-

I2. Tant «trullo» com «talego", en el sentit de "presó», apareixen recollits a Pomares (I997: 30I i 310). 
panyada d'un mínim context), fent constar que cap d'ells no apareix a l'És a dir, ni com a «no admissible» ni com d' «ús restringit»: «fa una calada a la pipa» (p. I6), «pijadetes tecnològiques» (p. I5; TV 3 tampoc admet «pijo»), «algo» (p. 2I), «jefe» (p. 22), «tu estaràs dins el portaequipatge» (p. 31), «vostè no ens importa un bledo» (p. 46), «Li van donar un susto de mort» (p. 56), «no em fas massa pena amb aquest aspecte» (p. 82), «la pitjor feina que es pot trobar en aquest mundillo» (p. 82), «Bueno» (p. 95), «tamany» (p. II4), «m’estava posant dels nervis» (p. 158; locució), «trola» (p. I74).

Finalment, a banda de presentar molts castellanismes, el GT mostra una manca de domini de la llengua per part de la traductora, que es percep en la vacil.lació («emprovadors» vs. «provadors», p. I55), en la ultracorrecció («El Max encara és sota els efectes del xoc», p. I79) i, sobretot, en anglicismes com «El Beaumont no està fet per fer temps al trullo» (p. 25) o «Però si és el Beaumont amb el cul lliure! Vine cap aquí i fes-me un cony d'abraçada!» (p. 27). En el primer exemple, l'expressió «fer temps» és un calc de anglès to do time (= "complir condemna»). I en el segon exemple, traducció de Look at you and your free ass. Come over here and give me a motherfuckin' hug (p. 24), hi ha dos calcs, un de lèxic, que consisteix a traduir la paraula ass per cul, i un de sintàctic, que consisteix a traduir motherfucking per un mot que ocupa el mateix lloc que l'anglès, és a dir, que va anteposat al nom. Com que no hi ha una correspondència exacta entre el guió original i la versió original, i per tant tampoc una correspondència exacta entre el guió original i el guió traduït, oferim una possible traducció en què no hi ha calcs: «Però si és el Baumont que ha sortit de la garjola! Vine aquí i fot'm una abraçada, collons!».

Quant al lèxic de la versió doblada (VD) i de la versió subtitulada (VS), constatem que és molt més normatiu que el del GT i que segueix, sobretot en la VD, com no podia ser d'altra manera, els criteris lingüístics establerts per Televisió de Catalunya (1995, 1997), que foren creats precisament per orientar els professionals dels mitjans audiovisuals (locutors, traductors, dobladors, etc.). Així, tant a la VD com a la VS trobem mots no normatius però acceptats per $\mathrm{TV}_{3}$ amb l'etiqueta d' "ús rentringit»: «nano" (VD: o:06:52 i VS: o:23:55), «tio» (VD: o:07:35), "pasma» en sentit de "policia» (VS: O:I6:33), «trena» en sentit de «garjola» (VD: o:I5:32), etc. És clar que també hi trobem mots que no accepten ni el DIECI ni el DIEC2: és el cas de «nòvio/-a» (VD i VS: I:I2:42), que per a TV3 pertanyen a l'«àmbit general» i no pas al «restringit».

A grans trets, podem afirmar que el lèxic de la VS és més informal (i, sovint, menys normatiu) que el de la VD. Així, «barco» (VS: o:05:40) contrasta amb «vaixell 
Dídac Pujol

Models de traducció literària $i$ audiovisual en català col-loquial

de pesca» (VD: 0:05:40), «està forrat» (VS: 0:05:5I) amb «s'ha fet milionari» (VD: 0:05:5I), «tot cristo» (VS: 0:06:06) amb «tots els cabrons» (VD: 0:06:06), «pasma» (VS: o:16:33) amb «polis» (VD: o:16:33), «algú molt cabrejat» (VS: o:35:26) amb «es va emprenyar» (VD: 0:35:26), «[els polis] venien a trincar-me» (VS: o:35:52) amb «[els polis] se'm volien emportar» (VD: 0:35:52), «Tens mam?» (VS: 0:45:40) amb «Tens res per beure?» (VD: 0:45:40), "Cagundena» (VS: o:46:32) amb «Merda» (VD: o:46:32), «acollonit» (VS: o:48:I8) amb «espantat» (VD: 0:48:I8), «pispes» (VS: 0:55:15) amb «lladres» (VD: 0:55:15), «porto 20 anys servint passatgers» (VS: 0:57:12) amb «he servit passatgers durant 20 anys» (VD: 0:57:12), «no és tonta» (VS: 0:58:22) amb «no és idiota» (VD: 0:58:22), «llavors» (VS: 1:03:28) amb «aleshores» (VD: 1:03:28), «Què cony passa aquí?» (VS: I:I7:42) amb «Què punyeta passa aquí?» (VD: I:I7:42), «[És] un conjunt que tinc clissat» (VS: $\mathrm{I}: 33: 45) \mathrm{amb}$ «És un vestit nou que ia tinc vist» (VD: I:33:45), «aparcarem aquest trasto» (VS: I:55:05) amb «Deixarem la camioneta» (VD: I:55:05) i «que li fotés un gec d'hòsties» (VS: 2:II:20) amb «que li havia d'haver fotut una hòstia» (VD: 2:II:20).

A diferència dels casos esmentats en el paràgraf anterior, en què la VS era més informal que la $\mathrm{VD}$, trobem poques ocurrències en què la VD sigui la més informal. En donem alguns exemples representatius: «Gairebé mai compro novetats» (VS: 0:53:29) contrasta amb el més informal «No compro gaires novetats» (VD: O:53:29), i «Li queda molt bé» (VS: I:40:50) i «Et queda molt bé» (VS: I:4I:33) contrasten, respectivament, amb «Li queda la mar de bé [el vestit]» (VD: I:40:50) i «Et queda de conya» (VD: I:4I:33).

En alguns casos, la VS, com el GT, cau en l'anglicisme, per exemple "Qui t'ha salvat el cul?» (VS: o:15:32), mentre que la VD utilitza expressions més genuïnes com "Qui t'ha salvat la pell?» (VD: O:I5:32). Tant a la VD com a la VS hi trobem algun castellanisme esporàdic, com l'ús de «recollir» en comptes de "passar a buscar», que suposem que és fruit d'un descuit o bé del desconeixement dels correctors: "La nit que em va venir a recollir [a la presó]» (VD: I:I9:40), «[demà] et recullo» (VS: o:16:I7). També hi ha alguns castellanismes volguts, com "polla» (VS i VD: o:48:48): malgrat que no aparegui recollida al DIECI, al DIEC2 ni a l'És a dir, la VD i la VS no tenen cap recança a l'hora d'utilitzar aquest mot en la seva accepció sexual, segurament perquè de mica en mica ha anat desplaçant les formes més tradicionals «cigala» $\mathrm{i}$ «titola». 


\section{CONCLUSIONS}

Al llarg d'aquest article hem vist que cadascun dels tres textos meta, és a dir, el guió traduït (GT), la versió doblada (VD) i la versió subtitulada (VS), s'emmarca en un model de traducció diferent.

Entrant en cadascun dels nivells de llenguatge analitzats en aquest article, si comparem la fonètica del GT, de la VD i de la VS constatem que el model de llengua utilitzat en el GT té una clara voluntat de reflectir la pronúncia col-loquial, i que per aconseguir això trenca les convencions ortogràfiques mitjançant canvis ortogràfics (respellings) de diversa mena: assimilació («endivina»), epèntesi («ideia») i, principalment, elisió, tant dins d'un mot («re») com, sobretot, en el pla sintàctic («no 't preocupis»). La VS, en canvi, és molt més conservadora pel que fa als canvis ortogràfics que reflecteixen la pronúncia col-loquial, i es limita a fer un parell de canvis molt puntuals: «sisplau» (en comptes de "si us plau») $\mathbf{i}$ "peli» (en comptes de "pel-lícula»). La fonètica de la VD es troba, comparativament, a mitjà camí entre l'ortodòxia formal de la VS i el trencament volgut de la norma del GT. D'altra banda, si comparem la VD amb l'estàndard oral proposat per l'IEC (I996a), veiem que s'hi ajusta força (apartat 6 , exemples $\mathrm{I}-5$ ), cosa que provoca, a vegades, pronúncies excessivament formals (apartat 6, exemples I-2). Val a dir que, sempre que l'IEC dóna la possibilitat de fer la pronúncia col-loquial, s'opta per aquesta forma («ia», «pendre»), però que en casos no previstos per l'IEC s'alterna la formalitat amb la informalitat (apartat 6, exemples 6-7), la qual cosa fa que la pronúncia quedi, sovint, una mica allunyada de la de la parla informal i espontània.

Pel que fa a la morfologia, l'única característica col-loquial compartida pel GT, la VD i la VS és l'ús del participi «sigut» en comptes d' «estat», una opció que, tot i no estar prevista per l'IEC (I996b), apareix com a possible a TVC (1997). Llevat del cas de «sigut», la VD i la VS no s'aparten ni un mil.límetre de l'estàndard normatiu dictat per l'IEC, de manera que, en l'aspecte morfològic almenys, trobem una rigidesa que bandeja opcions ben vives i col-loquials com «aviam», «aixins», «dugues», «vem» (= «vam»), «sapiguer» $\mathbf{O}$ «eleganta». Això és extensible també al GT, que és lleugerament més informal que la VD i la VS en tant que s'atreveix a utilitzar formes col-loquials no sancionades per l'IEC: «digue-li» (en comptes de «digues-li») i «estés» (en comptes d'«estigués»). Sigui com sigui, hom té la impressió que en els models de traducció utilitzats s'ha explotat molt poc el ventall de recursos morfològics col-loquials de 
Dídac Pujol

Models de traducció literària i audiovisual en català col-loquial

què disposa el català, de manera que la morfologia present en la traducció literària i audiovisual contribueix a crear la sensació (en el lector i, encara més, en l'espectador) d'una llengua encarcarada, poc àgil i excessivament formal i pautada.

Les sintaxis del GT, de la VD i de la VS són força diferents. Si bé comparteixen trets col-loquials com l'ús de pleonasmes i de "per» en comptes de "per a», la sintaxi del GT conté més trets col-loquials que la VD i la VS, sobretot l'ús no normatiu de la combinació pronominal «els hi». De fet, l'anàlisi que hem realitzat a l'apartat 8 ens permet establir una gradació en què el GT presenta una sintaxi més col-loquial i la VS una sintaxi menys col.loquial, de manera que la VD es troba en un punt intermedi. Val a dir, però, que les virtuts col-loquials de la sintaxi del GT queden desvirtuades per una sèrie de problemes dels quals estan exemptes la VD i la VD, i que fan perdre naturalitat al text meta. Així, al GT hi ha solucions excessivament formals i encarcarades («li'n», «li n'han»), calcs de l'estructura juxtaposada de les frases angleses i, per si fos poc, una sintaxi castellana, tant en l'ús de la preposició «a» davant de complement directe com en l'afegitó o l'elisió de pronoms ("Ja se't passarà», "I això què cony té a veure?»).

El lèxic del GT és molt diferent del de la VD i de la VS. El vocabulari que s'utilitza a la VD i a la VS segueix, llevat d'algunes excepcions puntuals (com «polla» en comptes de «titola»), els criteris lingüístics dictats per Televisió de Catalunya (1995 i 1997), que han estat recollits i ampliats posteriorment a l'És a dir. Tot amb tot, s'observa que el lèxic de la VS és, en general, més informal i menys normatiu que el de la VD, cosa que fa que la VD tingui un punt no tant d'encarcarament com de contenció lingüística que li impedeix explotar al màxim el registre col-loquial. El GT, en canvi, utilitza el «català que ara es parla» i aposta clarament per un model de traducció basat en la llengua que es parla al carrer, la qual cosa fa que el text meta abundi en castellanismes lèxics, un recurs que (cal deixar-ho ben clar) no és l'únic que s'hi utilitza per indicar col.loquialitat.

Voldríem constatar també que el model de doblatge de $\mathrm{TV}_{3}$ analitzat aquí coincideix força amb les descripcions que n'han fet, entre d'altres, Santamaria (1997: 90-92), Izard Martínez (1999: 349-35I), Ainaud, Espunya i Pujol (2003: 135-I39 i I48156) i Bassols i Segarra (eds., 2009): a grans trets, aquests estudis conclouen que la fonètica, la morfologia i la sintaxi emprades en el doblatge de $\mathrm{TV}_{3}$ són bastant (o molt) normatius i relativament poc col-loquials (a vegades fins i tot formals i encarcarats), mentre que el lèxic és relativament informal i habitualment normatiu (tot i que ho 
és menys que en els altres nivells de llengua). Dit d'una manera encara més breu: la col-loquialitat, $\mathrm{TV}_{3}$ la transmet sobretot a través del lèxic.

Ja per acabar, per tot el que s'ha dit podem concloure amb una visió més general: si haguéssim de situar els tres models de traducció en un espectre de més formal a més informal, l'ordre seria, sens dubte, VS, VD i GT. A grans trets, el GT és el més trencador, sobretot en dos àmbits: el de la representació fonètica, que defuig la representació ortogràfica convencional; i el de la tria lèxica, on s'utilitzen molts més castellanismes que en la VD i la VS. En tots els casos, la morfologia és força conservadora i poc transgressora respecte al català estàndard i les possibilitats col.loquials que ofereix el català. Pel que fa a la sintaxi, el GT és el que explota més els recursos de la llengua, seguit de la VD i, en últim terme, la VS, que presenta una sintaxi força estàndard. Tot amb tot, el caràcter genuïnament col-loquial de la sintaxi del GT queda desvirtuat pels castellanismes i anglicismes, que no sabem si són volguts (un intent de reproduir el "català que ara es parla») o si responen a una manca de domini de l'idioma — no sabem fins a quin punt el corrector d'estil de l'editorial Empúries va intervenir en la traducció, si és que hi va intervenir. ${ }^{13}$ Finalment, el lèxic del GT abunda en castellanismes, suposem que intencionats, cosa que contrasta amb la VD i la VS, que utilitzen un vocabulari col-loquial molt més depurat de castellanismes.

\section{CODA}

Sense poder-hi aprofundir per manca d'espai i deixant la feina de demostració per a un futur article, ens limitem a formular dues hipòtesis que ens podrien ajudar a situar el model de traducció col-loquial del GT en un marc més ampli: a) el GT va ser, en el seu moment (1998), una evolució i una transgressió respecte a models de traducció anteriors com El vigilant en el camp de sègol de J. D. Salinger (traducció d'Ernest Riera i Josep M. Fonalleras, 1990) i Pigmalió de Bernard Shaw (traducció de Xavier Bru de Sala, 1997); ${ }^{14}$ i b) aquest caràcter «transgressor» que reclamava Pujolar (1997: 284) pocs mesos abans que es publiqués el GT beu, en el cas de Jackie Brown,

I3. Per a un cas d'intervenció del corrector que acaba afectant el model de llengua en traducció, vegeu Pijuan Vallverdú (2007).

I4. Per a una comparació del Pigmalió de Shaw adaptat per Joan Oliver (I957) i traduït per Xavier Bru de Sala (1997), vegeu Boix-Fuster (2006). 
de dues fonts: la primera, la parla popular que ha sentit al carrer la traductora; i la segona, el model de traducció que, dos anys abans, el I995, establia Josep Julià en la seva traducció de la novel.la de Carlo Emilio Gadda Quell merdé hurrible de via Merulana.

Dídac Pujol

Universitat Pompeu Fabra didac.pujol@upf.edu

\section{REFERÈNCIES BIBLIOGRÀFIQUES}

Ainaud, J., A. Espunya \& D. Pujol (2003) Manual de traducció anglès-català, Vic, Eumo.

Bartoll, E. (20I2) La subtitulació. Aspectes teòrics i pràctics, Vic, Eumo.

Bassols, M. (2009) «El col.loquial dels mitjans», dins M. Bassols \& M. Segarra, eds. (2009: 9-20).

Bassols, M., A. Rico \& A. M. Torrent, eds. (1997) La llengua de TV/3, Barcelona, Empúries.

Bassols, M. \& M. Segarra, eds. (2009) El col.loquial dels mitjans de comunicació, Vic, Eumo / Universitat de Vic.

Bibiloni, G., C. Castellanos \& Ll. Marquet (2006) «El procés d'elaboració de la llengua catalana, prenent com a referència l'elaboració verdagueriana", Anuari Verdaguer. Revista d'estudis literaris del segle XIX, I4, pp. 253-26I.

BladAs, Ò. (2009) «La llengua oral col.loquial», dins M. Bassols \& M. Segarra, eds. (2009: 2I-39)

Borx-Fuster, E. (2006) «Els Pigmalions catalans de Joan Oliver i Xavier Bru de Sala: dues aportacions separades per quaranta anys", Els Marges, 78, pp. 55-78.

Brumme, J., ed. (2008) La oralidad fingida: descripción y traducción. Teatro, cómic y medios audiovisuales, Madrid / Frankfurt, Iberoamericana / Vervuert.

- (2012) Traducir la voz ficticia, Berlín, De Gruyter.

Brumme, J. \& A. Espunya, eds. (2012) The Translation of Fictive Dialogue, Amsterdam / Nova York, Rodopi.

BRUMme, J. \& H. Resinger, eds. (2008) La oralidad fingida: obrasliterarias. Descripción $y$ traducción, Madrid/Frankfurt, Iberoamericana/Vervuert. 
Cabré, Ll. \& M. Ortín (1984) «Aproximació a Josep Carner, traductor (Els anys de l'Editorial Catalana: 1918-192I)", Els Marges, 3I, pp. II4-I25.

Chaume, F. (2003) Doblatge i subtitulació per a la TV, Vic, Eumo.

Comissió de Normalització Lingüística TVC (1993) Orientacions lingüistiquesper al doblatge, Barcelona, Televisió de Catalunya.

Consell de l'Audiovisual de Catalunya (2007) La qualitat de la llengua en els mitjans audiovisuals, monogràfic de Quaderns del CAC 28, Barcelona, Consell de l'Audiovisual de Catalunya. [Disponible a: <http://www.cac.cat/pfw_files/ $\mathrm{cma} /$ recerca/quaderns_cac/Q28.pdf>.]

Corporació Catalana de Mitjans Audiovisuals (2013) Llibre d'estil de la Corporació Catalana de Mitjans Audiovisuals. Guia editorial. Manual d'ús, Barcelona, Generalitat de Catalunya. [Disponible a: <http://www.ccma.cat/libredestil >.] ÉS A DIR. <http://esadir.cat>. [Portal lingüístic de la Corporació Catalana de Mitjans Audiovisuals]

Feliu, F. (2008) «Esmolar la llengua, a la forja de les traduccions», dins M. Casacuberta, et alii (eds.), La llengua de 1907, Girona, CCG, pp. I09-I28.

FORCADELL, M. (2OI2) «The (mis)rendering of informationally marked structures in fictive orality: English in situ accent-shift into Catalan», dins J. Brumme \& A. Espunya, eds. (2012: 185-198).

- (2013) «La sintaxi catalana en procés de canvi: la desaparició de la dextralocació en el català de TV3", Estudis Romànics, 35, pp. 4OI-4I4.

GadDa, C. E. (1995) Quell merdé hurrible de via Merulana, traducció de Josep Julià, Barcelona, Proa.

Garolera, N. (20I4) «El català que ara es parla. La degradació de la llengua als mitjans de comunicació", Els Marges, I03, pp. I75-182.

Gifreu, J. (20I4) El català a l'espai de comunicació. El procés de normalització de la llengua als mèdia (I976-2013), Bellaterra / Castelló de la Plana / Barcelona / València, Universitat Autònoma de Barcelona / Universitat Jaume I / Universitat Pompeu Fabra / Universitat de València.

Grup D’Estudis Catalans (1992) El barco fantasma (1982-1992), Barcelona, Llibres de l'Índex.

Grup Flaix, comp. (2009) Diccionari del català col.loquial. Dubtes davant del micròfon, Barcelona, Enciclopèdia Catalana.

Institut d'Estudis Catalans [IEC] (I995) Diccionari de la llengua catalana [DIECI], Barcelona / Palma de Mallorca / València, Edicions 3i4 / Edicions 62 / Editorial 
Dídac Pujol

Models de traducció literària $i$ audiovisual en català col-loquial

Moll / Enciclopèdia Catalana / Publicacions de l'Abadia de Montserrat. [Disponible a: <http://diecr.iec.cat/diecr/entrada/diec.asp >.]

- $\left(1996 \mathrm{a}^{2}\right)$ [1990] Proposta per a un estàndard oral de la llengua catalana. I Fonètica, Barcelona, Institut d'Estudis Catalans. [3a edició revisada (1998) disponible a: $<$ http://publicacions.iec.cat/repository/pdf/oooooo62/00000072.pdf>.]

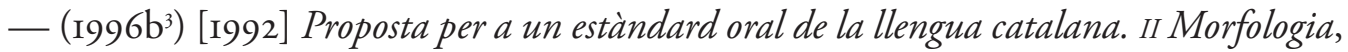
Barcelona, Institut d'Estudis Catalans. [4a edició revisada (1998) disponible a: $<$ http://publicacions.iec.cat/repository/pdf/oooooo62/o0000073.pdf>.]

- (2007) Diccionari de la llengua catalana [DIEC2], Barcelona, Edicions 62 / Enciclopèdia Catalana. [2a edició; disponible a: <http://dlc.iec.cat>.]

Izard Martínez, N. (I999) «Traducció audiovisual i creació de models de llengua en el sistema cultural català. Estudi de cas del doblatge d' "Helena, quina canya!"”, tesi doctoral, Barcelona, Universitat Pompeu Fabra. [Disponible a: $<$ http://www. tdx.cat/handle/10803/7436>.]

KAILUWEIT, R. (2002) "Català heavy / català light: una problemàtica de la "lingüística de profans" ", Zeitschrift für Katalanistik, I5, pp. I69-I82. [Disponible a: <http:// latina.phil2.uni-freiburg.de/pusch/zfk/is/kailuweit.pdf>.]

Lacreu, J. (20067) [1990] Manual d'ús de l'estàndard oral, València, Universitat de València.

Lamuela, X. \& J. Murgades (1984) Teoria de la llengua literària segons Fabra, Barcelona, Quaderns Crema.

Llengua i Mèdia (2004) La subtitulació del col-loquial, Bellaterra, Universitat Autònoma de Barcelona.

Marco, J. (2000) «Funció de les traduccions i models estilístics: el cas de la traducció al català al segle XX», Quaderns. Revista de traducció, 5, pp. 29-44.

Paloma, D. (2009) «El català de les sèries de televisió», dins M. Bassols \& M. Segarra, eds. (2009: 57-74).

Payrató, Ll. (19963) [1988] Català col-loquial. Aspectes de l'ús corrent de la llengua catalana, València, Universitat de València.

Pazos, M. Ll. (2007) [1990] L'amenaça del català light, Barcelona, La Busca. [Edició original: Barcelona, Tibidabo, 1990].

Pericay, X. \& F. Toutain (1986) Verinosa llengua, Barcelona, Empúries.

- (1996) El malentès del noucentisme. Tradició i plagi a la prosa catalana moderna, Barcelona, Proa. 
Pijuan Vallverdú, A. (2007) «Anàlisi del mecanoscrit i la correcció de la traducció de Manuel de Pedrolo de Llum d'agostı, Quaderns. Revista de traducció, I4, pp. 57-66.

Pinyol, R. \& P. Quer (2006) «Les aportacions de Verdaguer a la llengua literària segons els seus coetanis", Anuari Verdaguer. Revista d'estudis literaris del segle $X I X, \mathrm{I} 4$, pp. 4OI-4I8.

Pitarra, S. (20I4) Singlots poètics. Teatre complet, 2 vols., Tarragona, Arola / Universitat Rovira i Virgili.

PlA, A. (2008) «Juerga catalana», La diferencia, El Volcán Música, cançó II [CD].

Pomares, J. (1997) Diccionari del català popular i d'argot, Barcelona, Edicions 62.

Pujolar, J. (1997) De què vas, tio?, Barcelona, Empúries.

Sabater, E. (I99I) $N i$ «heavy», ni «light»: català modern!, Barcelona, Empúries.

Salinger, J. D. (1990) El vigilant en el camp de sègol, traducció d'Ernest Riera i Josep M. Fonalleras, Barcelona, Empúries.

Santamaria, L. (1997) «Les sèries de producció aliena», dins M. Bassols, A. Rico \& A. M. Torrent, eds. (1997: 85-94).

- (2009) «La traducció del col-loquial de les telesèries», dins M. Bassols \& M. Segarra, eds. (2009: 233-245).

Sellent, J. (20I4) (I-2-20I4) «No aplego re de lo que diuen». [<http://www.nuvol. com/opinio/no-aplego-re-de-lo-que-diuen>]

Shaw, B. (1997) Pigmalió, traducció de Xavier Bru de Sala, Barcelona, La Magrana.

Soler Pardo, B. (2013) «Traducción y doblaje: análisis de fuck y su traducción al español en Jackie Brown", Entreculturas. Revista de traducción y comunicación intercultural, 6, pp. I27-I39. [Disponible a: <http://www.entreculturas.uma. es>, núm. 6.]

Tarantino, Q. (1998a) [1997] Jackie Brown, Londres, Faber [guió en anglès].

— (1998b) Jackie Brown, traducció de Laura Escorihuela, Barcelona, Empúries [guió en català].

- (dir.) (2002) [1997] Jackie Brown, Nova York / Barcelona, Miramax/Laurenfilm. [Enregistrament de vídeo en DVD. Versió original anglesa i doblada al català i al castellà; subtítols en anglès, català i castellà. Estudi de doblatge: Soundtrack (Barcelona). Versió catalana: traducció i adaptació de diàlegs d'Albert Pejó. Pellícula emesa per Televisió de Catalunya el dia I4-9-2000.]

Televisió de Catalunya [TVC] (1995) El català a TV3. Llibre d'estil, Barcelona, Edicions 62. 
Dídac Pujol

Models de traducció literària i audiovisual en català col-loquial

- (1997) Criteris lingüistics sobre traducció i doblatge, Barcelona, Edicions 62.

Toutain, F. (1997) «Traducció i models estilístics», dins S. González Ródenas \& F. Lafarga (eds.), Traducció i literatura. Homenatge a Ángel Crespo, Vic, Eumo, pp. 63-72.

Tubau, I. (1990) El català que ara es parla. Llengua i periodisme a la ràdio i la televisió, Barcelona, Empúries.

Vallverdú, F. (2000) El català estàndardi ielsmitjans audiovisuals, Barcelona, Edicions 62. 